\title{
A new miniaturized magnetometer system for long-term distributed observation on the seafloor
}

\author{
Kazunori Ogawa ${ }^{1 *}$, Tetsuo Matsuno 1,2, Hiroshi Ichihara ${ }^{2,3}$, Kazuo Nakahigashi ${ }^{2,4}$ and Nobukazu Seama ${ }^{1,2}$
}

\begin{abstract}
We have developed a new magnetometer system specialized to multipoint and long-term observations on the seafloor to promote marine or ocean-bottom experiments mainly for the electromagnetic sounding of the Earth's interior. In situ magnetic field observation on the seafloor is an essential geophysical technique to investigate structures of the oceanic crust and the upper mantle, many of which are still frontier as to observational evidences. The in situ and long-term observations require long-term-operable and small-size magnetometer systems, which are placed on the seafloor over a year in pressure-resistant cases without external power supply and communication. We have designed and developed a new electric circuit board of small size and lower power consumption for the magnetometer system. Our new magnetometer system, what we call "DOKODEMO MAG," is suitable to be installed in a pressure-resistant cylinder of $36 \mathrm{~mm}$ diameter and can operate independently over 2 years with a smaller amount of batteries than the conventional system because its power consumption was saved to $33 \mathrm{~mW}$. This magnetometer system is capable of observing orthogonal three-axis magnetic fields continuously with sampling frequency of $5 \mathrm{~Hz}$ at maximum and an accuracy of $\sim 0.1 \mathrm{nT}$. The system also records tilt and temperature of the system and voltage of the batteries. Prototype models of this magnetometer system were tested for in situ operation for 5 months on the seafloor around the Kikai caldera in the south of the Kyusyu Island, SW Japan. The results of the test showed sufficient performance of our new magnetometer system and its potential of future usage for every type of marine or oceanbottom operations.
\end{abstract}

Keywords: New magnetometer system, Small size, Low power consumption, Long-term observation, Electromagnetic sounding

\section{Introduction}

Geophysical observations are fundamental tools to probe the internal structure of the Earth, and the increase in the number of observation sites would result in higher resolution of the probing. Examples at stationary observation sites are GNSS geodetic observations in GEONET Japan, seismic observations in Hi-net Japan, and multigeophysical observations in US EarthScope, which have performed important roles to understand crustal deformation, seismic and volcanic activities, and internal structure in the Earth (e.g., Ozawa et al. 2011; Ito et al.

*Correspondence: kazunori.ogawa@topaz.kobe-u.ac.jp

${ }^{1}$ Department of Planetology, Kobe University, Kobe, Japan

Full list of author information is available at the end of the article
2007; Schmandt and Humphreys 2010). Land-based multipoint electromagnetic investigations have been enabled by the development of simplified and low-cost instruments, and they have also revealed detailed electrical resistivity distributions than ever (e.g., Ichiki et al. 2015; Yang et al. 2015). All these previous studies indicate that in situ observations with the increasing number of geophysical observation sites are a powerful approach to reveal geodynamics.

Multipoint electromagnetic investigations on the seafloor at temporal observation sites also have a high potential to probe crustal and upper mantle structure. There were a few experiments with relatively large number of observation sites across the East Pacific Rise (Baba et al. 2006; Key et al. 2013), the Mariana subduction system 
(Matsuno et al. 2010), and the Cocos Plate subduction zone (Naif et al. 2013), which provide critical geophysical constraints for understanding their geodynamics beneath the seafloor. Nevertheless, the number of experiments on the seafloor is limited comparing to those on land because of high cost for multipoint seafloor surveys. In fact, a large number of observation units are required for dense three-dimensional observations, and these units usually become large in size because the system requires waterproof containers and deployment/retrieval mechanisms, which results in occupations on research vessels and high costs. Such properties of the seafloor instruments crucially hamper marine observations at multipoint and in large scale. One important way to enhance opportunities for the seafloor multipoint observations is miniaturization of the observation systems.

In this paper, we introduce a magnetometer system that was newly designed and developed with specializing for multipoint seafloor observations. The main concept of the system design is simplification and miniaturization. The new magnetometer system is suitable to be installed in a small submarine package. This small system is capable of operating in the isolated seafloor environment for over 2 years by low power consumption, which allows us to attach it to other seafloor instruments such as an ocean-bottom seismometer for example. We also introduce the first results of an in situ operational test on the seafloor around the Kikai caldera, Japan, by using prototype models of the new magnetometer system. These results showed desired performance and sufficient potential of the system for future multipoint simultaneous observations.

\section{System requirements for observing temporal geomagnetic field variations on seafloor}

The long-term distributed geomagnetic observations on the seafloor require four main characteristics for the individual magnetometer systems: high measurement accuracy, small size, easy handling, and low cost. We primarily targeted on miniaturization in our developments of the new magnetometer system with keeping its measurement quality as conventional fluxgate-type magnetometers. The magnetometer system has to be enclosed in water-and-pressure-tight spheres or cylinders of non-magnetic materials for the seafloor measurements. A positive buoyancy and a detachable weight are also required for recovery. The whole system is deployed from vessels to be placed on the seafloor, and it is recovered at the end of an observation period onto the vessel using a self-pop-up instrument by releasing the weight to accent it with the positive buoyancy. When the size of the magnetometer system becomes smaller, the pressure container and the positive buoyancy should become smaller, which leads the whole system to be easier to handle and also to reduce costs because only smaller pressure container and less positive buoyancy are required.

The miniaturization of the magnetometer system can be achieved by downsizing the magnetometer system itself and also by saving power consumption in the electrical circuit. Since the magnetometer systems are powered by batteries encapsulated together in the containers, saving power consumption directly reduces the system size because the entire volume of batteries occupies a large part in the pressure container. We assumed a titanium pressure cylinder of inner diameter $36 \mathrm{~mm}$ for a standard model of our magnetometer system as the goal of the miniaturization, because it is the minimum size to contain the commercially available high-capacity DD-size lithium battery, which has been commonly used in conventional seafloor systems. A currently available pressure cylinder with its inner diameter of $55 \mathrm{~mm}$ was assumed for a prototype model that was used for operational tests.

The new magnetometer system measures triaxial geomagnetic field strength, and temperature and tilt of the magnetometer sensor. Performances required for the geomagnetic field measurements are derived from the strength of Earth's main field as background, and fluctuation range and frequency of the local geomagnetic variation (e.g., Jacobs 1987). These are roughly defined as dynamic range of $\pm 60,000 \mathrm{nT}$, accuracy of $\sim 0.1 \mathrm{nT}$, and sampling frequency of $>2 \mathrm{~Hz}$. The sampling frequency of $>2 \mathrm{~Hz}$ is somewhat over specification for natural source marine electromagnetic sounding methods (e.g., Baba et al. 2017), but we chose it for possible applications of electromagnetic sounding on land and of future control source marine electromagnetic sounding, and for possible observation of tsunami induced magnetic field (e.g., Ichihara et al. 2013). Temperature measurements are also necessary to correct temperature-dependent drifts of fluxgate magnetometer outputs. We estimated that temperature accuracy of better than $1{ }^{\circ} \mathrm{C}$ is sufficient for our magnetometer system, while it depends on types of the magnetometer sensor. A clinometer in the system should have a resolution of better than $1^{\circ}$ for three axes, which allows us to transform coordinate system of the geomagnetic field data from the magnetometer sensor coordinate system to the earth coordinate system. We note that this accuracy of the clinometer is not capable of correcting attitude changes of the magnetometer sensor due to perturbation by submarine water flow and crustal movements, but its data can be used for detection of such attitude changes.

We assumed that 2 years of operation time is long enough for the magnetometer system, because the temporal geomagnetic field variation should be continuously observed for over 1 year for electrical resistivity 
imaging down to deeper depths like the bottom of the upper mantle with higher accuracy. Operable duration of the magnetometer system is constrained by a lifetime of batteries and a memory capacity for data recording. The battery voltage should be monitored and recorded constantly as the battery voltage slowly decreases with power consumption during the long-term operation. The voltage data are useful after the recovery to investigate health condition of the magnetometer system during the operation.

\section{System configuration, functions, and specifications}

We have designed and manufactured two types of new electrical circuit boards, the prototype model and the standard model: The prototype model was used for an in situ operation test on the seafloor, and the standard model finally satisfied all the requirements mentioned in the previous sections. In this section, we describe configuration, functions, and specifications of the new magnetometer system. The instrumental concept and some parts of detailed electrical designs of this system were derived from a space instrument, the deployable camera system (DCAM3) onboard asteroid probe Hayabusa2 (Ogawa et al. 2017; Watanabe et al. 2017) because they share some system requirements and functions in common, such as miniaturization and low power consumption techniques.

A functional block diagram of our new magnetometer system is shown in Fig. 1a, and a setup of the magnetometer system is shown in Fig. 1b, c. The system consists of an internal part and an external part of the pressure cylinder. The control board in the internal part, which is the main development object in this study, has the following major functions: (1) collecting measurement signals and storing these data in the memory, (2) power control, and (3) clock control. The external part consists of an external board and a GPS board, and it allows us to set up the magnetometer system and check its status before deployment and after recovery via a water-resistant connector. Since the connection between the external part and the internal part can be achieved without opening the pressure cylinder, we can easily handle the magnetometer system even on swaying vessels. Furthermore, the external part is available for maintenance and test run of the control board by connecting directly to the control board in laboratory.

The main controller collects measurement signals of the magnetometer sensor, the clinometer sensor, the temperature gauge, and the battery voltmeter. We chose three-axis fluxgate sensor, Bartington Mag648, for the magnetometer sensor because this is capable of satisfying the above-mentioned requirements: dynamic range $\pm 60,000 \mathrm{nT}$, accuracy better than $0.1 \mathrm{nT}$, power consumption $\sim 15 \mathrm{~mW}$, and the small size of $29 \times 23 \times 66 \mathrm{~mm}$ (packaged model). The 24-bit A/D converters in front of the CPU receive signals from the magnetometer sensor that is originally generated as $\pm 3 \mathrm{~V}$ for each axis magnetic field and convert the analog signals to digital. One issue in the magnetic field sampling was a selection of the voltage reference IC for these A/D converters. The choice of the IC affects performance of the A/D converters and the total power consumption by several $\mathrm{mW}$. As a result of a trade-off study for several types of ICs, we selected two types of them, MAX6126 and LT1461, and manufactured three prototype boards as one board for MAX6126 and other two boards for LT1461. After performance tests of the prototype models, MAX6126 was finally selected for the standard model. The sampling frequency of the magnetometer is $5 \mathrm{~Hz}$ at maximum, that of the clinometer is every hour, and those of the other sensors are every $60 \mathrm{~s}$ by default. These sampling frequencies are also configurable by presets for target observations. The acquired data are intermittently stored in the microSD card on the control board, which has sufficient capacity ( $>5$ GByte) for 2-year continuous observations. Ancillary data for flags that indicate whether the control board is just sampling tilt, temperature, and battery voltage, and whether the board is just writing data in the microSD card. We noticed that these flags are essential because these actions often make noises in the magnetic field samplings.

The power control includes the following three functions: (1) receiving electrical power from batteries or an external power supply and providing power to the whole system, (2) a switch for the battery power line, and (3) monitoring the battery voltage. While the primary batteries work for the main electrical power source during observations, the power also can be supplied by an external power source connected to the control board. The latching relay on the battery power line can be switched by a voltage signal from the external board to start using the batteries just before deployment of the magnetometer system from the vessel. While battery voltage gradually decreases during seafloor observations, the controller board monitors the battery voltage and quits own operations with appropriate shutdown actions at the time of that the battery voltage reaches a configurable lower limit.

The time control is an important issue for observations. In particular, the sampling timing of the magnetic field is strictly managed with less than $0.1 \mathrm{~ms}$ error. The three A/D converters for three axes sample analog signals from the magnetometer at the same timing in parallel and hold them in registers until they are processed. The CPU keeps internal clock time by signals from the crystal oscillator counter, and it controls sampling timing for 


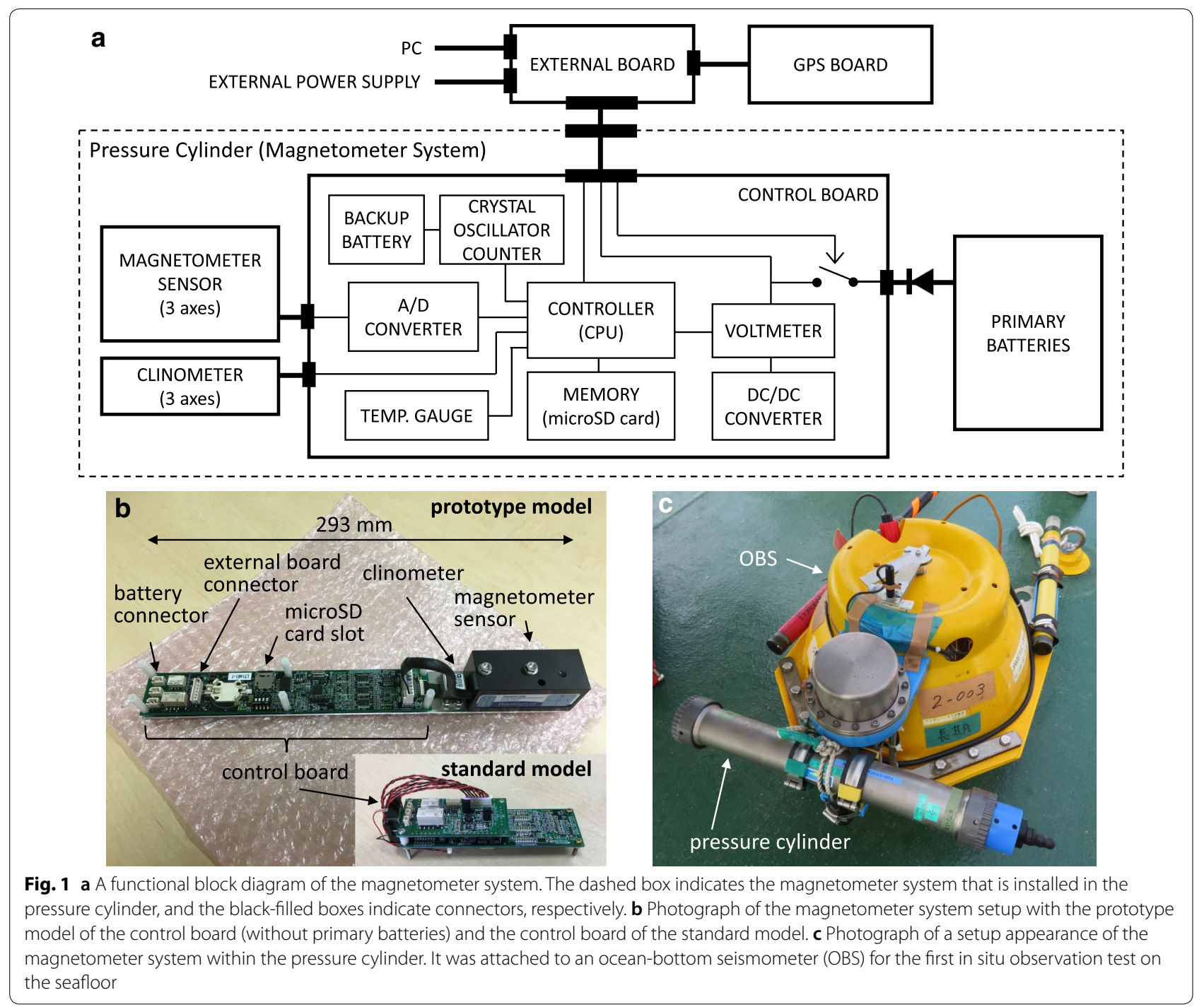

the sensors. The internal clock time is corrected by synchronizing with 1 PPS signals from the GPS board with its accuracy of less than $0.1 \mathrm{~ms}$, and the time difference before and after the correction is also recorded in the memory. The corrections are conducted before and after every seafloor observation to estimate and correct clock drifts in the entire operation period. The crystal oscillator counter has an additional button battery on the control board to keep the counter survived in case the primary battery power is lost during operations. Even if it would happen, the CPU could automatically recover the internal clock time using the surviving counter when power is supplied again.

Our new magnetometer system was assembled through integrating the control board, the magnetometer sensor, and the clinometer onto an aluminum plate, and this system was installed into the pressure cylinder with primary batteries (Fig. 1b). The envelope size of the system except for batteries is the followings; the prototype model is $33 \times 35 \times 293 \mathrm{~mm}$ for a cylinder of $55 \mathrm{~mm}$ inner diameter, and the standard model is $\Phi 35 \times 180 \mathrm{~mm}$ for a cylinder $36 \mathrm{~mm}$ inner diameter, respectively. The standard model has the smaller volume because its control board has simply a two-tiered structure with a cable binding them. Typical average of total power consumption of the prototype model was measured as $\sim 36 \mathrm{~mW}(\sim 320 \mathrm{Wh} /$ year) including power for the sensors. Power consumption of the standard model is slightly lower at low voltage input, $33 \mathrm{~mW}$ at $3.8 \mathrm{~V} \mathrm{(} \mathrm{290} \mathrm{Wh/year).} \mathrm{These} \mathrm{low}$ power consumption characteristics allow the magnetometer system to operate for 1 year by three cells of DD-size $(33.5 \mathrm{~mm}$ diameter $\times 111.5 \mathrm{~mm})$ lithium battery. The 
entire volume of the system including batteries is sufficiently small to be installed in small pressure cases that are readily deployed at multiple points in the ocean. The system specifications are summarized in Table 1.

\section{Test operation of new magnetometer system}

We conducted the first in situ operation test of the new magnetometer systems by using the prototype models to measure geomagnetic field variation for 5 months on the seafloor. This operation test was performed in the Kikai caldera, $50 \mathrm{~km}$ south from Kyusyu Island in Japan, as a part of a large exploration project (Tatsumi et al. 2018). The three prototype models were attached to one oceanbottom electromagnetometer (OBEM) at observation site OBM1 and to two ocean-bottom seismometers (OBSs, in Fig. 1c) at sites OBM2 and OBM3. The locations of each observation site are shown on a map in Fig. 2. The water depths at sites OBM1, OBM2, and OBM3 are 390, 450, and $310 \mathrm{~m}$, respectively. The OBEM at site OBM1 also included a conventional magnetometer (Tierra Tecnica Corp.) for comparison of data sets; this magnetometer has been widely used among the Japanese marine electromagnetic (EM) research group in many projects including international projects (e.g., Baba et al. 2017; Matsuno et al. 2010). The prototype models were installed in commercially available pressure cylinders of inner diameter 55 and $70 \mathrm{~mm}$ with two primary battery cells of DDsize lithium battery. The geomagnetic field observations were conducted for 5 months from October 17, 2016 (deployed), to March 3, 2017 (recovered).

The three prototype models of the magnetometer system successfully measured the geomagnetic fields for the entire observational period. Their measured magnetic field variations of the geomagnetic north and its perpendicular components ( $\mathrm{H}, \mathrm{D}$, and $\mathrm{Z}$ components) for 20 days are shown in Fig. 3a. The triaxial geomagnetic field data measured by each magnetometer system in its magnetometer sensor coordinate system were converted to the $\mathrm{H}, \mathrm{D}$, and $\mathrm{Z}$ components of the geomagnetic coordinate system by using available tilt data and comparing with the 12th generation of IGRF model (International Geomagnetic Reference Field; Thébault et al. 2015). These geomagnetic field variations show similar features to observation data of the conventional magnetometer (OBEM) at site OBM1 and that of the ground-based geomagnetic observatory of Kakioka, Japan (also shown in Fig. 3a). For more detail, slight differences in geomagnetic field variations among the sites were observed, and they should be due to difference in local and regional conductivity structure under each observation site.

The two data sets at site OBM1 from our new magnetometer system and from the conventional magnetometer show good agreements. We compared them
Table 1 Main specifications of the magnetometer systems for the prototype model and the standard model, which are distinguished by the type of the control board

\begin{tabular}{|c|c|c|}
\hline Item & Prototype model & Standard model \\
\hline $\begin{array}{l}\text { Acceptable power source volt- } \\
\text { age }\end{array}$ & $2.7-15 \mathrm{~V}$ & $2.4-25 \mathrm{~V}$ \\
\hline Time synchronization accuracy & $0.1 \mathrm{~ms}$ & $0.1 \mathrm{~ms}$ \\
\hline \multicolumn{3}{|l|}{ Magnetic field ( 3 axes) } \\
\hline Dynamic range & $\pm 60,000 \mathrm{nT}$ & $\pm 60,000 \mathrm{nT}$ \\
\hline Accuracy (noise floor $\sigma$ ) & $<0.12 \mathrm{nT}$ & $<0.06 \mathrm{nT}$ \\
\hline Bit depth & 24 bits & 24 bits \\
\hline Sampling frequency & $<5 \mathrm{~Hz}^{\mathrm{a}}$ & $<5 H z^{a}$ \\
\hline \multicolumn{3}{|l|}{ Tilt (3 axes) } \\
\hline Accuracy & $0.1^{\circ}$ & $0.1^{\circ}$ \\
\hline Bit depth & 16 bits & 16 bits \\
\hline Sampling frequency & $<1 \mathrm{~Hz}$ & $<1 \mathrm{~Hz}$ \\
\hline \multicolumn{3}{|l|}{ Temperature } \\
\hline Dynamic range & -40 to $+125^{\circ} \mathrm{C}$ & -40 to $+125^{\circ} \mathrm{C}$ \\
\hline Accuracy & $<0.5^{\circ} \mathrm{C}$ & $<0.5^{\circ} \mathrm{C}$ \\
\hline Bit depth & 12 bits & 12 bits \\
\hline Sampling frequency & $<1 \mathrm{~Hz}$ & $<1 \mathrm{~Hz}$ \\
\hline \multicolumn{3}{|l|}{ Battery voltage } \\
\hline Accuracy & $5 \mathrm{mV}$ & $5 \mathrm{mV}$ \\
\hline Bit depth & 16 bits & 16 bits \\
\hline Sampling frequency & $<1 \mathrm{~Hz}$ & $<1 \mathrm{~Hz}$ \\
\hline Power consumption@3.8V input & Typ. 36 mW & Typ. 33 mW \\
\hline Power consumption @7.0V input & Typ. 36 mW & Typ. 36 mW \\
\hline System size (without batteries) & $33 \times 35 \times 293 \mathrm{~mm}$ & $\Phi 35 \times 180 \mathrm{~mm}$ \\
\hline Operating lifetime & $>2$ years & $>2$ years \\
\hline
\end{tabular}

a Internal electrical activities (measuring tilt, temperature, and voltage, and storing data) periodically corrupt magnetic field data of $1.7 \%$ at maximum (see the main text for details)

by induction vectors and a transfer function of each horizontal component between them. They were calculated by BIRRP (Chave and Thomson 2004) using data between October 25, 2016, and November 3, 2016, together with those from the Kakioka geomagnetic observatory as remote reference data. The induction vectors (shown in Fig. 2) are well fitted with $95 \%$ confidence limits (two standard deviations), and the error of the induction vector for our new magnetometer system is slightly smaller than those for the conventional magnetometer. The transfer functions and the coherences (Fig. 4) indicate that the two data sets are nearly identical with their period of above $16 \mathrm{~s}$ that are generally used for natural source marine electromagnetic sounding methods (e.g., Baba et al. 2017). In contrast, these become less similar as the period becomes shorter than $16 \mathrm{~s}$, probably indicating that the geomagnetic variation signals in the shorter period become too low to be detected by the two 


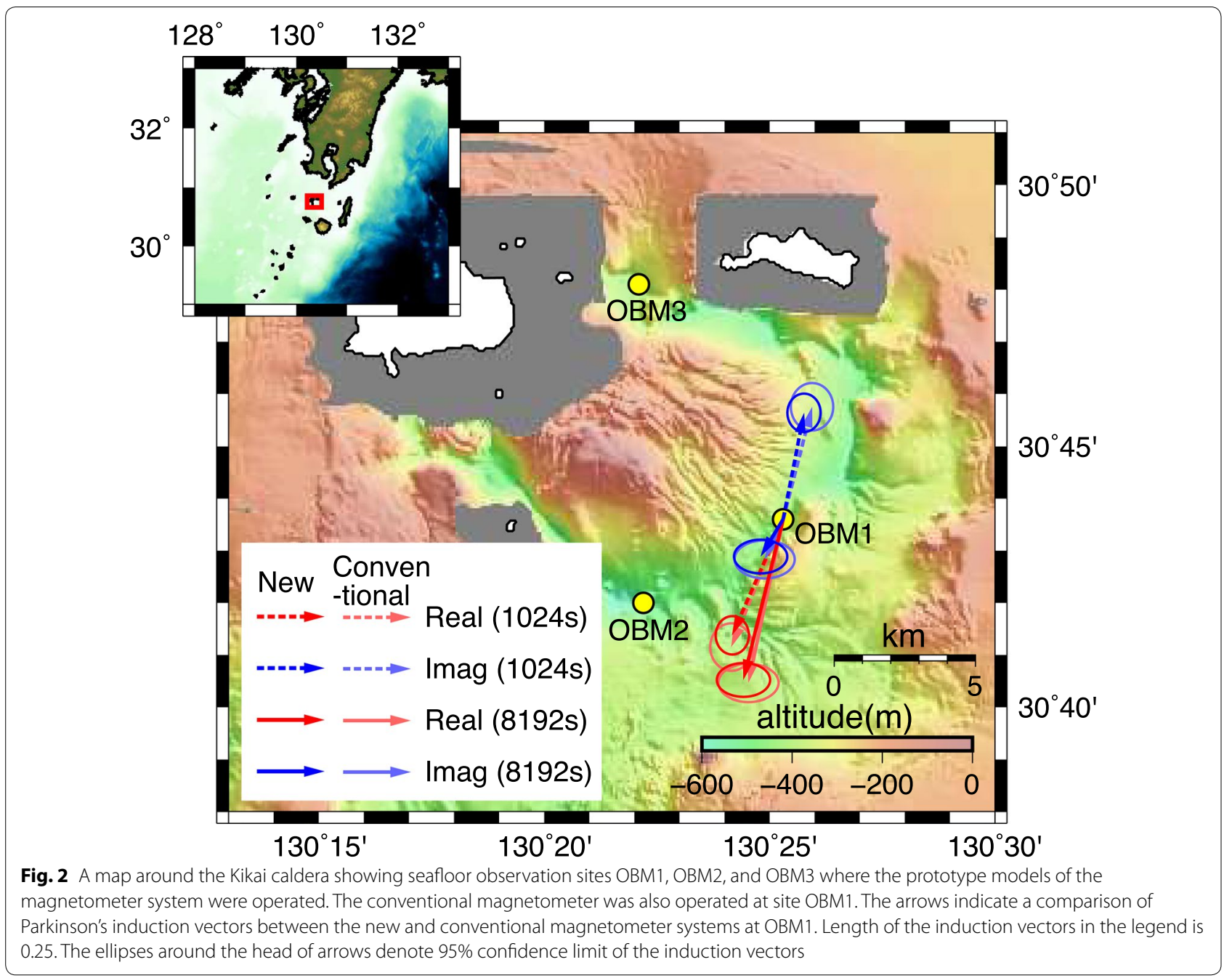

magnetometers due to high attenuation of the electromagnetic field in the conductive seawater.

The results from the first in situ operation test also provided useful information to improve the standard model design: (1) choice of the voltage reference IC for the A/D converters, (2) affection to magnetic field measurement by the other measurements, and (3) connection to clinometers. First, the choice of the voltage reference IC for the A/D converters was well related to noise floor of $\sim 1 \mathrm{~Hz}$ in the magnetic field measurements. Three-axistotal standard deviation of 60-s magnetic field variation (in October 22 for example) was estimated to be $0.054 \mathrm{nT}$ at site OBM3 that is much smaller than those at sites OBM1 and OBM2 (0.117 and $0.115 \mathrm{nT}$, respectively) and that of the conventional magnetometer at site OBM1 $(0.105 \mathrm{nT})$. We have found this difference is caused by the voltage reference IC for the A/D converters; the prototype models at sites OBM1 and OBM2 have LT1461 and that at site OBM3 has MAX6126. The test results suggested the latter one is suitable in this design and the prototype model with this IC showed better performance than the others. Second, magnetic field measurement was affected by the other measurements within the same magnetometer system. The geomagnetic data have a bias of several $\mathrm{nT}$ when the control boards were just measuring tilt, temperature, and primary battery voltage, and writing data on the microSD card (Fig. 3b). Such noisy data can be simply removed with referring to the flags in the ancillary headers, because it leads small data loss rate $(1.7 \%$ at maximum) that is acceptable for most marine electromagnetic sounding purposes using longterm observations. We note that this data corruption rate can be mitigated by reducing frequency of sampling ancillary data and storing data. Third, the two prototype models lost tilt data of one axis at site OBM1 and all axes at site OBM3. We found that the loss of the tilt data was due to bad electrical contacts at the connectors between 


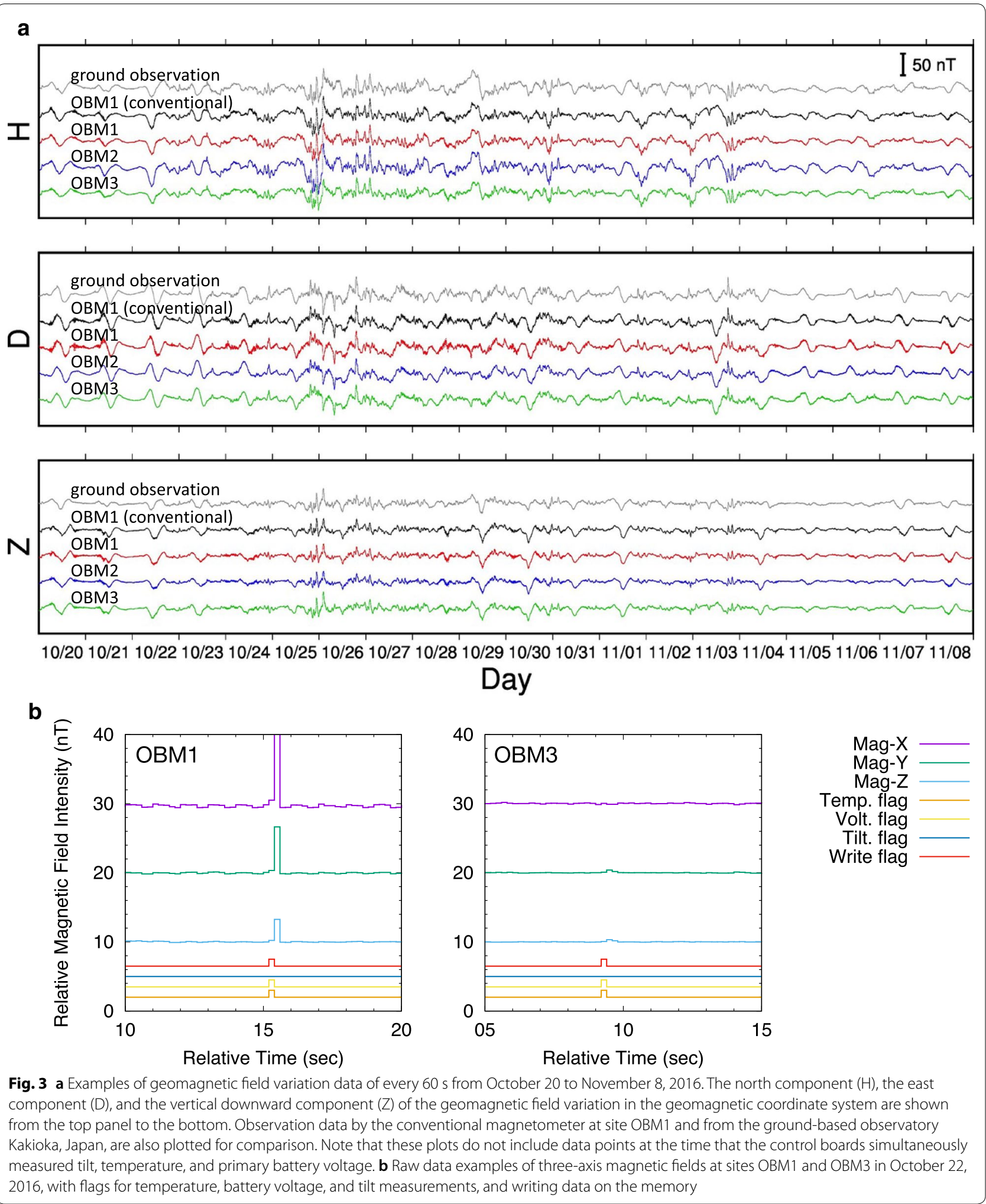




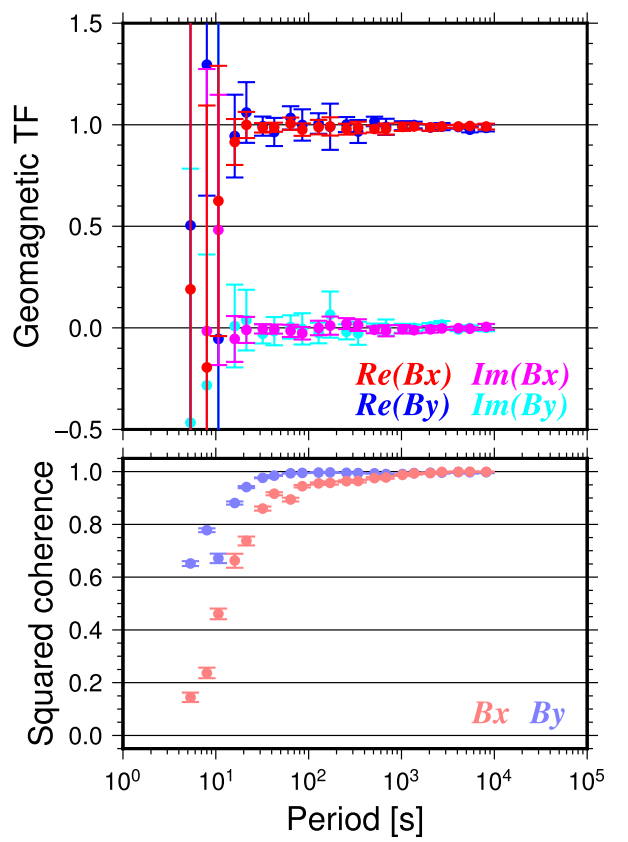

Fig. 4 Geomagnetic transfer functions and squared coherences between the new and conventional magnetometer systems at site OBM1. Bx and By indicate north and east components of geomagnetic field, respectively. The error bars represent 95\% confidence intervals. The same geomagnetic signal is recorded when the real and imaginary components are 1 and 0 , respectively

the control boards and the clinometers. All these results were used to improve the design of the standard model.

\section{Summary}

The miniaturized magnetometer system has been developed for long-term in situ observations and for future multipoint observations of geomagnetic field variation on the seafloor. This system can record geomagnetic field with sampling frequency of $5 \mathrm{~Hz}$ as well as tilt, temperature, and primary battery voltage every $60 \mathrm{~s}$ (configurable) with hardware statuses. The three prototype models of the new magnetometer system were used for the first in situ operation test for 5 months, and they successfully measured and recorded geomagnetic field variations during the test period. The data indicated the desired performance of the new magnetometer system and provided useful information to improve the design of the standard model. The observed geomagnetic field variations showed good agreements with observation data of the conventional magnetometer and of the ground-based geomagnetic observatory at Kakioka. The measurement accuracy of magnetic field satisfied the requirement of $\sim 0.1 \mathrm{nT}$ in the best model with the appropriate voltage reference IC for the A/D converters. The standard model was basically developed by the same electrical design to the prototype model for site OBM3, but some parts were optimized using the results from the first in situ operation test. It has the smaller envelope size $\Phi 35 \times 180 \mathrm{~mm}$ without batteries due to two-tiered electrical circuit boards, and the lower power consumption of $33 \mathrm{~mW}$ at $3.8 \mathrm{~V}$ input voltage which results from an optimization of DC/DC converters. The standard model can be installed with batteries in a small pressure cylinder of $36 \mathrm{~mm}$ inner diameter and $550 \mathrm{~mm}$ length for 1-year observation for example, and this size is highly effective to deploy a number of the magnetometers on multiple sites simultaneously. Since this new magnetometer system is aimed to deploy in all future marine or ocean-bottom geophysical missions both by stand-alone use and by attached to any kind of ocean-bottom instruments such as OBS, we named this system "DOKODEMO MAG" meaning "magnetometer everywhere" in Japanese.

\section{Abbreviations}

A/D: analog to digital; CPU: central processing unit; DC/DC: direct current to direct current; GEONET: GNSS Earth Observation Network System; GNSS: global navigation satellite system; GPS: global positioning system; Hi-net: high-sensitivity seismograph network; IC: integrated circuit; IGRF: International Geomagnetic Reference Field; OBEM: ocean-bottom electromagnetometer; OBM: ocean-bottom magnetometer; OBS: ocean-bottom seismometer; PPS: pulse per second.

\section{Authors' contributions}

The authors conducted all of this study and wrote the manuscript. All authors read and approved the final manuscript.

\section{Author details}

${ }^{1}$ Department of Planetology, Kobe University, Kobe, Japan. ${ }^{2}$ Kobe Ocean-Bottom Exploration Center (KOBEC), Kobe University, Kobe, Japan. ${ }^{3}$ Earthquake and Volcano Research Center, Nagoya University, Nagoya, Japan. ${ }^{4}$ Department of Marine Resources and Energy, Tokyo University of Marine Science and Technology, Tokyo, Japan.

\section{Acknowledgements}

The authors gratefully acknowledge the development efforts of Mr. Osamu Nara, Mr. Hirokazu Sato, Mr. Kaneyoshi Kuwata, and the engineers of Meisei Electric Co., Ltd. The authors thank the crews (Prof. Yoshiji Yano, captain) of the TN Fukae-maru and the onboard research members for their valuable help to develop and recover the instruments during two cruises. The Kakioka geomagnetic field data were downloaded from the digital data service site of the observatory of Japan Meteorological Agency (http://www.kakioka-jma. go.jp/obsdata/metadata/en/products). The authors thank two anonymous reviewers for helpful comments that improved this paper.

\section{Competing interests}

The authors declare that they have no competing interests.

\section{Availability of data and materials \\ Not applicable.}

\section{Consent for publication}

Not applicable.

Ethics approval and consent to participate

Not applicable. 


\section{Funding}

This work was partly supported by Grant-in-Aid for Scientific Research (B) (No.

15H03717), Japan Society for the Promotion of Science.

\section{Publisher's Note}

Springer Nature remains neutral with regard to jurisdictional claims in published maps and institutional affiliations.

Received: 15 February 2018 Accepted: 19 June 2018

Published online: 03 July 2018

\section{References}

Baba K, Chave AD, Evans RL, Hirth G, Mackie RL (2006) Mantle dynamics beneath the East Pacific Rise at 17 degrees S: Insights from the Mantle Electromagnetic and Tomography (MELT) experiment. J Geophys Res Solid Earth 111:B02101. https://doi.org/10.1029/2004jb003598

Baba K, Tada N, Matsuno T, Liang P, Li R, Zhang L, Shimizu H, Abe N, Hirano N, Ichiki M, Utada H (2017) Electrical conductivity of old oceanic mantle in the northwestern Pacific I: 1-D profiles suggesting differences in thermal structure not predictable from a plate cooling model. Earth Planets Space 69:111. https://doi.org/10.1186/s40623-017-0697-0

Chave AD, Thomson DJ (2004) Bounded influence magnetotelluric response function estimation. Geophys J Int 157:988-1006. https://doi. org/10.1111/j.1365-246X.2004.02203.x

Ichihara H, Hamano Y, Baba K, Kasaya T (2013) Tsunami source of the 2011 Tohoku earthquake detected by an ocean-bottom magnetometer. Earth Planet Sci Lett 382:117-124. https://doi.org/10.1016/j.epsl.2013.09.015

Ichiki M, Ogawa Y, Kaida T, Koyama T, Uyeshima M, Demachi T, Hirahara S, Honkura Y, Kanda W, Kono T, Matsushima M, Nakayama T, Suzuki S, Toh H (2015) Electrical image of subduction zone beneath northeastern Japan. J Geophys Res Solid Earth 120:7937-7965. https://doi.org/10.1002/2015j b012028

Ito Y, Obara K, Shiomi K, Sekine S, Hirose H (2007) Slow earthquakes coincident with episodic tremors and slow slip events. Science 315:503-506. https:// doi.org/10.1126/science.1134454

Jacobs JA (ed) (1987) Geomagnetism, vol 1. Academic Press Ltd., London
Key K, Constable S, Liu LJ, Pommier A (2013) Electrical image of passive mantle upwelling beneath the northern East Pacific Rise. Nature 495:499-502. https://doi.org/10.1038/nature11932

Matsuno T, Seama N, Evans RL, Chave AD, Baba K, White A, Goto T, Heinson G, Boren G, Yoneda A, Utada H (2010) Upper mantle electrical resistivity structure beneath the central Mariana subduction system. Geochem Geophys Geosyst 11:009003. https://doi.org/10.1029/2010gc003101

Naif S, Key K, Constable S, Evans RL (2013) Melt-rich channel observed at the lithosphere-asthenosphere boundary. Nature 495:356-359. https://doi. org/10.1038/nature11939

Ogawa K, Shirai K, Sawada H, Arakawa M, Honda R, Wada K, Ishibashi K, lijima Y, Sakatani N, Nakazawa S, Hayakawa H (2017) System configuration and operation plan of Hayabusa2 DCAM3-D camera system for scientific observation during SCI impact experiment. Space Sci Rev 208:125-142. https://doi.org/10.1007/s11214-017-0347-7

Ozawa S, Nishimura T, Suito H, Kobayashi T, Tobita M, Imakiire T (2011) Coseismic and postseismic slip of the 2011 magnitude-nine Tohoku-Oki earthquake. Nature 475:373-376. https://doi.org/10.1038/nature10227

Schmandt B, Humphreys E (2010) Complex subduction and small-scale convection revealed by body-wave tomography of the western United States upper mantle. Earth Planet Sci Lett 297:435-445. https://doi. org/10.1016/j.epsl.2010.06.047

Tatsumi Y, Suzuki-Kamata K, Matsuno T, Ichihara H, Seama N, Kiyosugi K, Nakaoka R, Nakahigashi K, Takizawa H, Hayashi K, Chiba T, Shimizu S, Sano M, Iwamaru H, Morozumi H, Sugioka H, Yamamoto Y (2018) Giant rhyolite lava dome formation after 7.3 ka supereruption at Kikai caldera, SW Japan. Sci Rep 8:2753. https://doi.org/10.1038/s41598-018-21066-w

Thébault E, Finlay CC, Beggan CD et al (2015) International geomagnetic reference field: the 12th generation. Earth Planets Space 67:79. https://doi. org/10.1186/s40623-015-0228-9

Watanabe S, Tsuda Y, Yoshikawa M, Tanaka S, Saiki T, Nakazawa S (2017) Hayabusa2 mission overview. Space Sci Rev 208:3-16. https://doi.org/10.1007/ s11214-017-0377-1

Yang B, Egbert GD, Kelbert A, Meqbel NM (2015) Three-dimensional electrical resistivity of the north-central USA from Earth Scope long period magnetotelluric data. Earth Planet Sci Lett 422:87-93. https://doi.org/10.1016/j. epsl.2015.04.006

\section{Submit your manuscript to a SpringerOpen ${ }^{\circ}$ journal and benefit from:}

- Convenient online submission

- Rigorous peer review

- Open access: articles freely available online

- High visibility within the field

Retaining the copyright to your article

Submit your next manuscript at $\gg$ springeropen.com 